\title{
On the effect of titanium on quenching sensitivity and pseudoelastic response in a Fe-Mn-Al-Ni-base shape memory alloy
}

\author{
M. Vollmer ${ }^{1, *}$, P. Krooß ${ }^{1,}$, I. Karaman ${ }^{2}$, T. Niendorf ${ }^{1}$ \\ ${ }^{1}$ Universität Kassel, Institut für Werkstofftechnik (Materials Engineering), 34125 Kassel, \\ Germany \\ ${ }^{2}$ Department of Materials Science and Engineering, Texas A\&M University, College \\ Station, TX 77843, USA
}

\begin{abstract}
In the present study, the effect of $\mathrm{Ti}$ addition on the heat treatment procedures and pseudoelastic properties of a Fe-Mn-Al-Ni shape memory alloy were investigated. By replacing 1.5 at.\% $\mathrm{Al}$ through $\mathrm{Ti}$ in $\mathrm{Fe}-\mathrm{Mn}-\mathrm{Al}-\mathrm{Ni}$, it was possible to strongly hamper the formation of the ductile, non-transforming $\gamma$-phase, which is detrimental to the pseudoelastic performance. Single crystalline samples were fabricated via abnormal grain growth. Following aging treatment at $250^{\circ} \mathrm{C}$ compression testing at various testing temperatures was conducted up to $10.5 \%$ strain using a near $\langle 102\rangle$ oriented single crystal. A low Clausius-Clapeyron slope and good pseudoelastic properties were found.
\end{abstract}

Keywords: martensitic phase transformation, abnormal grain growth, superelasticity, precipitates, FeMnAlNiTi 
Due to relative low costs for alloying elements and good workability compared to conventional shape memory alloys (SMAs), iron based SMAs have attracted considerable attention in the last decade [1-10]. However, some of the main drawbacks hindering widespread application of firstly developed alloys are the high discrepancy between theoretical and experimental transformation strains, very low transformation temperatures, and the non-thermoelastic nature of martensitic transformation. In 2010 Tanaka et al. [11] reported a Fe-Ni-Co-Al based alloy system undergoing a thermoelastic transformation between a $\gamma$ parent phase and an $\alpha^{\prime}$ product phase resulting in large reversible strains up to $13 \%$. One year later, in 2011, Omori et al. [12] discovered an Fe-Mn-Al-Ni alloy, which is characterized by an unusual thermoelastic transformation between an $\alpha$ bcc parent phase and a $\gamma^{\prime}$ fcc product phase exhibiting a low Clausius-Clapeyron (CC) slope of $0.53 \mathrm{MPa} /{ }^{\circ} \mathrm{C}$ over a wide temperature range between $196^{\circ} \mathrm{C}$ and $240^{\circ} \mathrm{C}$. They were able to show excellent pseudoelasticity of more than $5 \%$ strain in the polycrystalline state with a relative grain size exceeding the cross section of the sample. The grain size was accomplished by a cyclic heat treatment, resulting in abnormal grain growth (AGG) $[12,13]$. Since then a considerable number of studies focused on the single crystal behavior [14-16], the effect of thermo-mechanical processing [17-20], cyclic degradation [21] and processing by additive manufacturing [22] of Fe-Mn-Al-Ni SMAs.

Coherent nano-sized precipitates, i.e. a $\mathrm{L}_{2}$ ordered $\gamma^{\prime}-(\mathrm{Ni}, \mathrm{Fe}, \mathrm{Co})_{3}(\mathrm{Al}, \mathrm{Ta})$ phase in the $\mathrm{Fe}-\mathrm{Ni}-$ Co-Al based alloys [11] and a B2 ordered $\beta-(\mathrm{NiAl})$ phase in Fe-Mn-Al-Ni [12], are crucially needed in these new Fe-based SMAs to change the martensitic transformation character from non-thermoelastic to thermoelastic $[11,12,17]$. Before, it was shown that nano-sized B1 
ordered $\mathrm{NbC}$ precipitates were able to improve the functionality of Fe-Mn-Si based SMAs, due to the introduction of preferential nucleation sites for the stress-induced martensitic transformation and the provision of internal stress fields for reverse transformation [23-25]. In addition to the significant impact of size, shape and volume fraction of the finely dispersed precipitates on the pseudoelastic behavior, a strong correlation between the formation of precipitates and hardness values of the materials has also been demonstrated [15,26-28].

In recent work it was shown that following solution heat treatment, precise control of the ductile $\gamma$-phase formation by variation of cooling conditions in Fe-Mn-Al-Ni is crucial in order to prevent grain boundary cracking [19]. However, the $\gamma$-phase is not desirable for attaining good pseudoelasticity [19], as this phase is non-transforming and, thus, dissipates the elastic strain energy associated with martensitic transformation in the matrix by non-reversible plastic deformation. The evolution of $\gamma$-phase is extremely rapid, a transfer time of parts from the furnace to the quenching medium of $5 \mathrm{~s}$ was sufficient to promote a fraction of about $40 \%$ of $\gamma$-phase [19]. Consequently, rapid chemical decomposition being responsible for $\gamma$-phase evolution during quenching of these alloys is a significant drawback against practical applications as this limits the sample cross sections that can be free of detrimental nontransforming phase and eventually show perfect pseudoelasticity.

With this background, the current study focuses on the addition of a small amount (1.5 at.\%) of titanium, which is known to be an $\alpha$-phase stabilizer [29], to the Fe-Mn-Al-Ni alloy in order to slow down $\gamma$-phase formation during quenching. In order to characterize the deformability of the alloy, an oligocrystalline structured, i.e. bamboo structured, tensile sample was tested at 
$20^{\circ} \mathrm{C}$. Vickers microhardness values were measured following various aging times and temperatures. Heat treatments were conducted in order to induce nano-sized precipitates, known to be crucial for thermoelastic martensitic transformation. Thermo-mechanical testing was carried out in the temperature range from $-150^{\circ} \mathrm{C}$ up to $20^{\circ} \mathrm{C}$ using a near $\langle 102\rangle$ oriented single crystalline compression sample grown utilizing AGG in order to determine the pseudoelastic performance of the alloy.

Ingots with a chemical composition of $\mathrm{Fe}-34.0 \% \mathrm{Mn}-15.0 \% \mathrm{Al}-7.5 \% \mathrm{Ni}-1.5 \% \mathrm{Ti}(\mathrm{at} . \%)$ and Fe-34.0\% Mn-16.5\% Al-7.5\% Ni (at.\%) used in this study were produced by vacuum induction melting using commercially pure metals. Small samples of $18 \mathrm{~mm}$ x $1.6 \mathrm{~mm} \times 1.5 \mathrm{~mm}$ from both alloys and compression samples with dimensions of $3 \mathrm{~mm} \times 3 \mathrm{~mm} \times 6 \mathrm{~mm}$ from Fe-MnAl-Ni-Ti were electro discharge machined. For heat treatment, the samples were sealed in quartz tubes under argon atmosphere. In order to investigate the $\gamma$-phase formation during slow cooling, Fe-Mn-Al-Ni and Fe-Mn-Al-Ni-Ti tensile samples were solution treated at $1225^{\circ} \mathrm{C}$ for $1 \mathrm{~h}$ to ensure a homogenous $\alpha$ structure and subsequently taken out of the furnace and cooled in ambient atmosphere to room temperature within 240 seconds (hereafter referred to air cooled). Microstructual analyses were conducted using a Keyence digital VH-100 optical microscope and a scanning electron microscope (SEM) operated at $20 \mathrm{kV}$ equipped with a backscattered electron detector (BSE detector). Samples for optical microscopy were mechanically polished to $1 \mu \mathrm{m}$ grit size and etched for one second using a solution of $3 \%$ nitric acid diluted in alcohol. Afterwards the Fe-Mn-Al-Ni-Ti sample was additional vibration-polished using colloidal $\mathrm{SiO}_{2}$ suspension with $0.05 \mu \mathrm{m}$ particle size to obtain surface quality needed for BSE imaging. 
In order to characterize the ductility of the grain boundaries, a tensile test was performed using a bamboo structured Fe-Mn-Al-Ni-Ti tensile sample. The sample was heat treated at $1225^{\circ} \mathrm{C}$ for $30 \mathrm{~min}$, cooled down with a cooling rate of $10^{\circ} \mathrm{C} / \mathrm{min}$ to $900^{\circ} \mathrm{C}$, held for $15 \mathrm{~min}$ at $900^{\circ} \mathrm{C}$ and finally heated up with a heating rate of $10^{\circ} \mathrm{C} / \mathrm{min}$ for a solution treatment at $1225^{\circ} \mathrm{C}$ for $1 \mathrm{~h}$ followed by air cooling. Afterwards, the sample was mechanically polished to $5 \mu \mathrm{m}$ grit size and the tensile test was performed using a MTS servo-hydraulic testing system in displacement control at a rate of $5 \mu \mathrm{m} / \mathrm{s}$. The strain was measured by an extensometer directly attached to gauge length. Afterwards, microstructural analyses were carried out using the optical microscope mentioned above.

Samples for aging studies and pseudoelastic testing were cyclically heat treated between $1225^{\circ} \mathrm{C}$ and $900^{\circ} \mathrm{C}$ for three times (holding times and cooling/heating rates as mentioned above) and finally solution treated at $1225^{\circ} \mathrm{C}$ for $1 \mathrm{~h}$ followed by air cooling. Afterwards, samples were mechanically polished to $5 \mu \mathrm{m}$ grit size and vibration-polished.

In order to measure the increase of hardness of the matrix due to aging, Vickers microhardness values were determined employing a force of $9.8 \mathrm{~N}$ for the bamboo structured sample shown in the inset of Fig. 2. The sample was wire cut and one sample was aged at $200^{\circ} \mathrm{C}$ for $10 \mathrm{~h}$, whereas another sample was aged at $250^{\circ} \mathrm{C}$ for different durations to form coherent nanoprecipitates. Electron-backscatter diffraction (EBSD) analyses were conducted to evaluate the grain orientations using the SEM mentioned above operated at $20 \mathrm{kV}$. 
For characterization of pseudoelastic performance a near $\langle 102\rangle$ orientated single crystalline compression sample, obtained via AGG, was tested in the pseudoelastic regime at different temperatures $\left(-150^{\circ} \mathrm{C},-90^{\circ} \mathrm{C},-40^{\circ} \mathrm{C}\right.$ and $\left.20^{\circ} \mathrm{C}\right)$ using the MTS servo-hydraulic testing system mentioned above. A cooling chamber equipped with a liquid nitrogen cooling system was used to allow for cryogenic mechanical testing. Temperatures have been measured by using a thermocouple mounted within the chamber. Tests were carried out in displacement control at a rate of $5 \mu \mathrm{m} / \mathrm{s}$ up to $1.5 \%$ strain measured by an extensometer directly attached to the compression grips. Finally, an incremental strain test at $20^{\circ} \mathrm{C}$ was performed up to a maximum strain of $10.5 \%$.

Figure 1 shows the optical micrographs of air cooled samples following a solution treatment at $1225{ }^{\circ} \mathrm{C}$ for $1 \mathrm{~h}$ for Fe-Mn-Al-Ni (Fig. 1a) and Fe-Mn-Al-Ni-Ti (Fig. 1b). As already reported in [19] non-rapid cooling of Fe-Mn-Al-Ni leads to second phase formation mainly at the grain boundaries with a serrated interface, due to a fast short-range diffusion of $\mathrm{Mn}$ and $\mathrm{Al}$ stabilizing the $\gamma$-phase. The same phenomena are shown in Figure 1a. This microstructural condition is detrimental for the pseudoelastic performance in two ways:

(i) $\gamma$-phase is a non-transforming phase, reducing the volume fraction of the microstructure showing a reversible phase transformation.

(ii) The serrated $\gamma-\alpha$ interfaces represent additional constraints with respect to the recoverability of martensitic transformation.

On the other hand, quenching in cold water leads to crack formation along the grain boundaries [19]. A thin layer of $\gamma$-phase at the grain boundaries is able to prevent intergranular cracking during quenching without notably affecting the pseudoelastic performance [19]. However, in 
Fe-Mn-Al-Ni, the cooling rates need to be extremely high to achieve this, which is not desirable in practical applications where relatively large cross sections are needed. Therefore, controlling the quenching sensitivity of the alloy is crucial in order to obtain an acceptable pseudoelastic performance in large scale components.

From Figure $1 \mathrm{~b}$ it is obvious that the $\gamma$-phase formation during air cooling in Fe-Mn-Al-Ni-Ti is strongly hampered, without any observable crack formation along the grain boundaries. Moreover, a thin layer of second phase is seen at the grain boundaries (inset of Figure 1b). Consequently, the addition of 1.5 at.\% Titanium seems to significantly slow down the decomposition during air cooling. In order to characterize the ductility of the grain boundaries during martensitic transformation, a tensile test was performed on a bamboo structured nonaged Fe-Mn-Al-Ni-Ti sample. It is well known that a large relative grain size is required for good performance in Fe-Mn-Al-Ni alloys due to incompatibility across grain boundaries upon martensitic transformation as a consequence of the lack of sufficient transformation systems to satisfy the compatibility $[12,14,18]$. Omori et al. [13] recently reported a new way to trigger AGG and achieve large grain sizes by a cyclic heat treatment between a single phase region and a two phase region in $\mathrm{Cu}-\mathrm{Al}-\mathrm{Mn}$ alloys, which has also been proven to be successful in FeMn-Al-Ni alloys [12,19-21]. Following this technique, Fe-Mn-Al-Ni-Ti samples were cyclically heat treated in the current study between $1225^{\circ} \mathrm{C}$ and $900^{\circ} \mathrm{C}$ in order to promote AGG. The stress-strain curve in Figure 1c clearly reveals a high strain level of about $9.5 \%$ before the sample failed. The critical stress $\sigma_{\text {crit }}$ (as defined in Figure 3) of about $310 \mathrm{MPa}$ is in good agreement with results of Omori et al. for polycrystalline Fe-Mn-Al-Ni [12] and Tseng et al. for $\langle 001\rangle$ oriented Fe-Mn-Al-Ni single crystals in tension [14]. However, the critical stress 
$\sigma_{\text {crit }}$ is strongly dependent of grain orientation, aging condition and additionally shows pronounced tension-compression asymmetry. The optical micrograph obtained after testing, shown in the inset of Figure 1c, revealed no crack formation along the grain boundary. A further increase in the amount of Titanium, i.e. to 3.0 at.\%, leads to a significantly increased brittleness (not shown). However, a more systematic study of the influence of different Titanium contents is out of the scope of the current work and, thus, will be subject of future work.

As mentioned above, the presence of finely dispersed coherent precipitates is crucial in Fe-MnAl-Ni based alloys to observe good pseudoelasticity $[12,15,19]$. Moreover, it is well known that the formation of finely dispersed precipitates strengthens the matrix in Fe-based SMAs and, thus, increases the hardness [15,26-28]. Tseng et al. [15] showed that the hardness of $\langle 001\rangle$ oriented Fe-Mn-Al-Ni single crystals increased from about $370 \mathrm{HV}$ to $430 \mathrm{HV}$ following a $10 \mathrm{~h}$ aging treatment at $200^{\circ} \mathrm{C}$. Moreover, they revealed a strong correlation between the precipitate size and the Vickers microhardness, and identified a precipitate size of $\sim 10 \mathrm{~nm}$ upon an aging treatment at $200^{\circ} \mathrm{C}$ for $3 \mathrm{~h}$. This peak aged condition showed the best pseudoelastic performance in Fe-Mn-Al-Ni. From Figure $2 \mathrm{a}$ it is obvious that an aging treatment at $200^{\circ} \mathrm{C}$ for $10 \mathrm{~h}$ in Fe-Mn-Al-Ni-Ti leads only to a slight hardness increase of about 20 HV1. Thus, taking into account the slower chemical kinetics as deduced from the inhibition of $\gamma$-phase evolution upon air cooling in Fe-Mn-Al-Ni-Ti, an aging heat treatment at $250^{\circ} \mathrm{C}$ was conducted using various aging times. The material hardness increased from $440 \mathrm{HV} 1$, following solution treatment, up to about $500 \mathrm{HV} 1$, following an $18 \mathrm{~h}$ aging heat treatment. A significant increase of hardness upon aging is already obtained after $15 \mathrm{~min}$ at $250^{\circ} \mathrm{C}$ and proceeds with a lower slope at longer aging durations (Figure 2). Currently, it is not clear, if 
the addition of Titanium changes the chemical composition of the nano-sized precipitates. However, this will be subject of future work. In order to achieve a compromise between sufficient matrix hardness and aging duration, a near $\langle 102\rangle$ oriented single crystalline Fe-MnAl-Ni-Ti sample obtained by AGG was aged for $3 \mathrm{~h}$ at $250^{\circ} \mathrm{C}$. The compression sample was loaded up to $1.5 \%$ total strain at temperatures ranging from $-150^{\circ} \mathrm{C}$ to $20^{\circ} \mathrm{C}$ and stress-strain responses with an almost perfect pseudoelastic recoverability are shown in Figure 3a. The calculated CC-Slope was found to be $0.34 \mathrm{MPa} /{ }^{\circ} \mathrm{C}$ (presented in the inset of Figure 3), which is similar to results found in $\langle 001\rangle$ compression samples in Fe-Mn-Al-Ni showing CC-Slopes between $0.3 \mathrm{MPa} /{ }^{\circ} \mathrm{C}$ and $0.41 \mathrm{MPa} /{ }^{\circ} \mathrm{C}$ upon different aging times at $200{ }^{\circ} \mathrm{C}$ [15]. The critical stress $\sigma_{\text {crit }}$ ranges from $658 \mathrm{MPa}$ up to $719 \mathrm{MPa}$ and the stress hysteresis is about $400 \mathrm{MPa}$, which is beneficial for damping applications [11]. This is almost twice of the critical stress $\sigma_{\text {crit }}$ and threefold of the stress hysteresis measured for the $\langle 001\rangle$ compression samples in Fe-MnAl-Ni aged at $200^{\circ} \mathrm{C}$ for $3 \mathrm{~h}$ [15]. Chemical purity of the alloys characterized could be influential as well, however, evaluation of this factor is currently not feasible.

Figure 4 shows the results of the incremental strain test conducted up to $10.5 \%$ at $20^{\circ} \mathrm{C}$. It is obvious from the inset of Figure 4 that the pseudoelastic recoverability was excellent up to about $3.5 \%$ transformation strain, i.e. $4.5 \%$ applied strain. At higher strains the recoverability strongly decreased and functional properties completely disappeared. In addition, no significant shape recovery was observable after heating the sample up to $400^{\circ} \mathrm{C}$ indicating a highly stabilized martensite. During the incremental strain test the applied stress increased from about $700 \mathrm{MPa}$ at the beginning of the stress plateau to about $1800 \mathrm{MPa}$ at $10.5 \%$ applied strain. It can be suggested that this strong increase of stress is related to the formation 
of dislocations in the matrix, which also correlates to the decreasing reversibility upon increasing applied strain. Moreover, it can be observed that the stress hysteresis strongly increased with increasing number of cycles, being a strong indicator for high dislocation activity and therefore a higher resistance to reverse transformation [30]. A rapid loss of the functional properties after a few cycles was shown in a functional fatigue test up to $3.2 \%$ nominal strain, where only a near $\langle 102\rangle$ orientated grain in a bamboo structured Fe-Mn-Al-Ni polycrystalline tension sample was activated [21]. Pronounced dislocation activity and distortion of pinned martensite were demonstrated in the latter study indicating that similar mechanism may be operative in the present case as well.

In summary, the present study investigated the role of titanium addition on quenching sensitivity and the pseudoelastic response of Fe-Mn-Ni-Al-based SMAs. A cyclic thermal treatment method resulted in abnormal grain growth leading to bamboo structured samples. Based on a variety of aging treatments and mechanical tests, the following conclusions can be drawn:

- Imposed by the addition of 1.5 at. $\% \mathrm{Ti}$, it was possible to significantly reduce the quenching sensitivity of Fe-Mn-Al-Ni, i.e. strongly hamper the $\gamma$-phase formation.

- It was shown that the formation of the ductile $\gamma$-phase was almost completely suppressed after air cooling from $1225^{\circ} \mathrm{C}$. Only grain boundaries were decorated with a thin layer of $\gamma$-phase avoiding crack formation and ensuring sufficient grain boundary ductility. 
- AGG induced by a cyclic heat treatment between $1225^{\circ} \mathrm{C}$ and $900^{\circ} \mathrm{C}$ was shown to form bamboo structured samples as well as relatively large single crystals in the Fe-Mn-Al-Ni-Ti alloy.

- An aging treatment at $250^{\circ} \mathrm{C}$ for various durations led to a significant increase in hardness. It is likely that this is connected with the formation of fine nano-sized precipitates.

- An excellent pseudoelastic behavior and a low CC-slope of $0.34 \mathrm{MPa} /{ }^{\circ} \mathrm{C}$ were demonstrated in compression tests at temperatures ranging from $-150{ }^{\circ} \mathrm{C}$ to $20^{\circ} \mathrm{C}$ up to $1.5 \%$ applied strain for a near $\langle 102\rangle$ oriented single crystalline sample.

- An incremental strain test at $20^{\circ} \mathrm{C}$ up to $10.5 \%$ applied strain revealed good pseudoelastic properties up to $4.5 \%$ applied strain. At higher applied strain levels, pseudoelastic performance deteriorated rapidly.

Financial support by Deutsche Forschungsgemeinschaft (Contract No. NI1327/7-1) is gratefully acknowledged. The U.S. part of the research was supported by the U.S. National Science Foundation (NSF), Division of Materials Research, Metals and Metallic Nanostructures Program, Grant No. 1508634, and NSF - U.S. National Science Foundation International Materials Institutes Program, Grant No. DMR 08-44082. The authors gratefully acknowledge Dr. Gregory Gerstein for his support during material production. 


\section{References}

[1] A. Sato, E. Chishima, K. Soma, T. Mori, Acta Metallurgica 30 (1982) 1177-1183.

[2] A. Sato, E. Chishima, Y. Yamaji, T. Mori, Acta Metallurgica 32 (1984) 539-547.

[3] C.M. Wayman, K. Ōtsuka, Shape memory materials, 1st ed., Cambridge University Press, Cambridge, New York, 1999.

[4] S. Kajiwara, Materials Science and Engineering: A 273-275 (1999) 67-88.

[5] A. Ariapour, D.D. Perovic, I. Yakubtsov, Metall and Mat Trans A 32 (2001) 16211628.

[6] A. Sato, H. Kubo, T. Maruyama, Materials Transactions 47 (2006) 571-579.

[7] T. Maki, K. Kobayashi, M. Minato, I. Tamura, Scripta Metallurgica 18 (1984) $1105-1109$.

[8] R. Hayashi, S.J. Murray, M. Marioni, S.M. Allen, R.C. O'Handley, Sensors and Actuators A: Physical 81 (2000) 219-223.

[9] Y. Tanaka, Y. Himuro, T. Omori, Y. Sutou, R. Kainuma, K. Ishida, Materials Science and Engineering: A 438-440 (2006) 1030-1035.

[10] H. Sehitoglu, I. Karaman, X. Zhang, Y. Chumlyakov, H. Maier, Scripta Materialia 44 (2001) 779-784.

[11] Y. Tanaka, Y. Himuro, R. Kainuma, Y. Sutou, T. Omori, K. Ishida, Science (New York, N.Y.) 327 (2010) 1488-1490.

[12] T. Omori, K. Ando, M. Okano, X. Xu, Y. Tanaka, I. Ohnuma, R. Kainuma, K. Ishida, Science (New York, N.Y.) 333 (2011) 68-71. 
[13] T. Omori, T. Kusama, S. Kawata, I. Ohnuma, Y. Sutou, Y. Araki, K. Ishida, R. Kainuma, Science (New York, N.Y.) 341 (2013) 1500-1502.

[14] L.W. Tseng, J. Ma, S.J. Wang, I. Karaman, M. Kaya, Z.P. Luo, Y.I. Chumlyakov, Acta Materialia 89 (2015) 374-383.

[15] L.W. Tseng, J. Ma, B.C. Hornbuckle, I. Karaman, G.B. Thompson, Z.P. Luo, Y.I. Chumlyakov, Acta Materialia 97 (2015) 234-244.

[16] L.W. Tseng, J. Ma, S.J. Wang, I. Karaman, Y.I. Chumlyakov, Scripta Materialia 116 (2016) 147-151.

[17] T. Omori, M. Nagasako, M. Okano, K. Endo, R. Kainuma, Appl. Phys. Lett. 101 (2012) 231907.

[18] T. Omori, M. Okano, R. Kainuma, APL Mater. 1 (2013) 32103.

[19] M. Vollmer, C. Segel, P. Krooß, J. Günther, L.W. Tseng, I. Karaman, A. Weidner, H. Biermann, T. Niendorf, Scripta Materialia 108 (2015) 23-26.

[20] T. Omori, H. Iwaizako, R. Kainuma, Materials \& Design 101 (2016) 263-269.

[21] M. Vollmer, P. Krooß, M.J. Kriegel, V. Klemm, C. Somsen, H. Ozcan, I. Karaman, A. Weidner, D. Rafaja, H. Biermann, T. Niendorf, Scripta Materialia 114 (2016) $156-160$.

[22] T. Niendorf, F. Brenne, P. Krooß, M. Vollmer, J. Günther, D. Schwarze, H. Biermann, Metall and Mat Trans A 47 (2016) 2569-2573.

[23] S. Kajiwara, D. Liu, T. Kikuchi, N. Shinya, Scripta Materialia 44 (2001) 28092814.

[24] A. Baruj, T. Kikuchi, S. Kajiwara, N. Shinya, Materials Science and Engineering: A 378 (2004) 333-336. 
[25] Z.Z. Dong, S. Kajiwara, T. Kikuchi, T. Sawaguchi, Acta Materialia 53 (2005) 4009-4018.

[26] T. Omori, S. Abe, Y. Tanaka, D.Y. Lee, K. Ishida, R. Kainuma, Scripta Materialia 69 (2013) 812-815.

[27] P. Krooß, M.J. Holzweissig, T. Niendorf, C. Somsen, M. Schaper, Y.I. Chumlyakov, H.J. Maier, Scripta Materialia 81 (2014) 28-31.

[28] J. Ma, B.C. Hornbuckle, I. Karaman, G.B. Thompson, Z.P. Luo, Y.I. Chumlyakov, Acta Materialia 61 (2013) 3445-3455.

[29] S. Lee, C.-Y. Lee, Y.-K. Lee, Journal of Alloys and Compounds 628 (2015) 4649.d Compounds 628 (2015) 46-49.

[30] J. Dadda, H. J. Maier, I. Karaman, Y. Chumlyakov, International Jounral of Materials Research 101 (2010) 1-11. 


\section{Figure Captions}

Figure 1: Optical micrographs of air cooled samples after solution treatment at $1225^{\circ} \mathrm{C}$ for $1 \mathrm{~h}$ for (a) Fe-34.0\%Mn-16.5\%Al-7.5\%Ni (at.\%) and (b) Fe-34.0\%Mn-15.0\%Al-7.5\%Ni-1.5\% Ti (at.\%). Inset of (b) shows a higher magnification BSE image of a grain boundary. The Stressstrain curve of a bamboo structured tension sample of Fe-34.0\% Mn-15.0\% Al-7.5\% Ni-1.5\% Ti is shown in (c). The inset depicts an optical micrograph of two grain separated by an almost straight grain boundary after testing.

Figure 2: Room temperature Vickers microhardness values in $\mathrm{Fe}-34.0 \% \mathrm{Mn}-15.0 \% \mathrm{Al}-7.5 \% \mathrm{Ni}-1.5 \% \mathrm{Ti}$ (at.\%) upon various aging times at $250^{\circ} \mathrm{C}$. For comparison a reference hardness value upon aging at $200^{\circ} \mathrm{C}$ is included. The inset shows the inverse pole figure (IPF) mapping normal to surface of the bamboo structured sample 
employed. Hardness measurements were conducted within the highlighted area normal to the surface shown.

Figure 3: Stress-strain diagrams from the compression tests up to $1.5 \%$ applied strain for a single crystalline $\mathrm{Fe}-34.0 \% \mathrm{Mn}-15.0 \% \mathrm{Al}-7.5 \% \mathrm{Ni}-1.5 \% \mathrm{Ti}$ (at.\%) sample (orientation is shown in the IPF) aged at $250^{\circ} \mathrm{C}$ for $3 \mathrm{~h}$. Tests were conducted at temperatures ranging from $-150^{\circ} \mathrm{C}$ up to $20^{\circ} \mathrm{C}$. The inset depicts the critical stress $\sigma_{\text {crit }}$ for the onset of martensitic transformation (as defined for the $-150^{\circ} \mathrm{C}$ hysteresis) at different temperatures and the calculated CC-Slope.

Figure 4: Incremental strain tests up to a total strain of $10.5 \%$ at $20^{\circ} \mathrm{C}$ for the same Fe-34.0\% Mn-15.0\%Al-7.5\% Ni-1.5\% Ti (at.\%) sample shown in Figure 3. The inset reveals the recoverable strain plotted against the transformation strain (excluding elastic strains). 

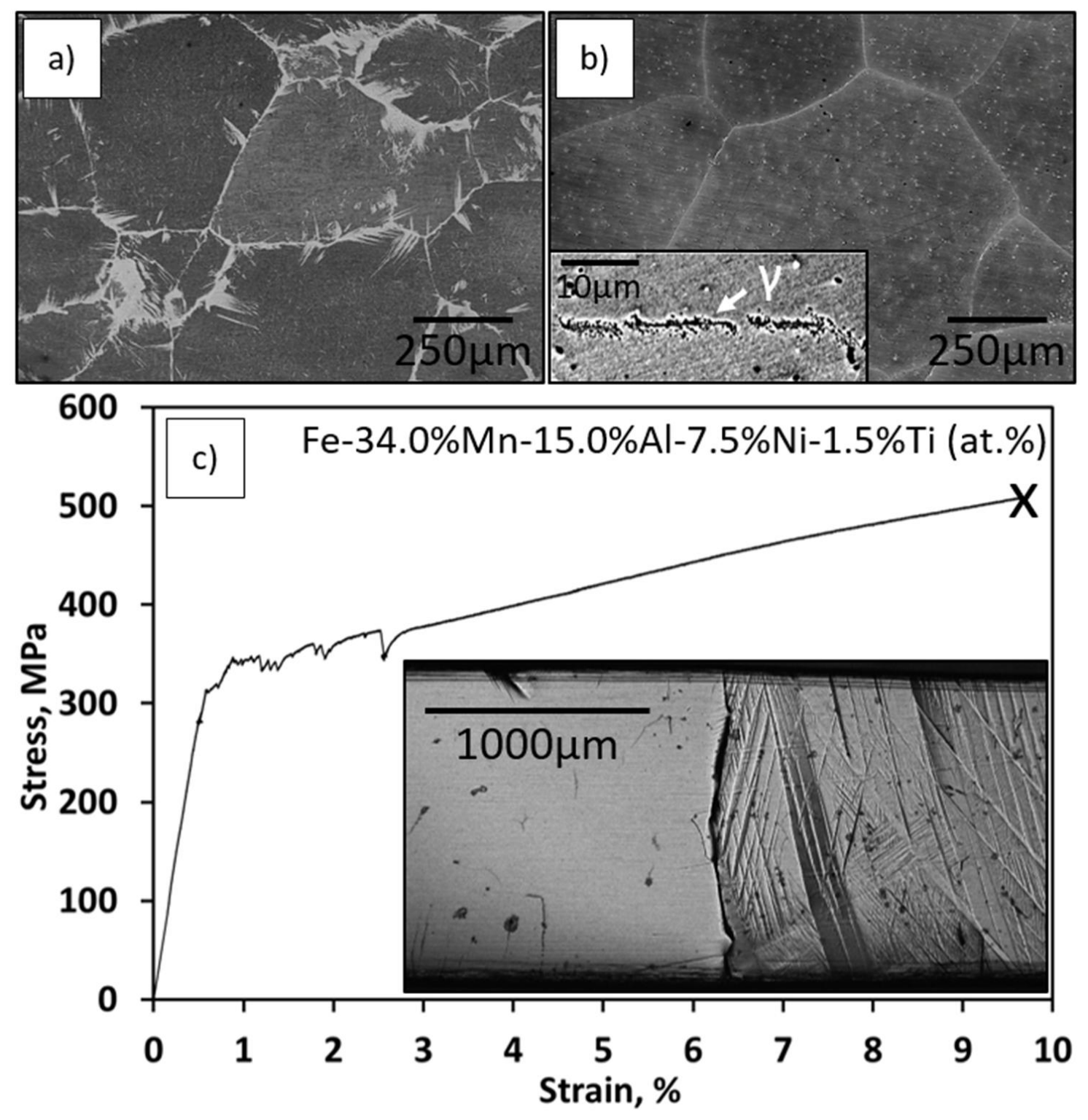

Figure 1 


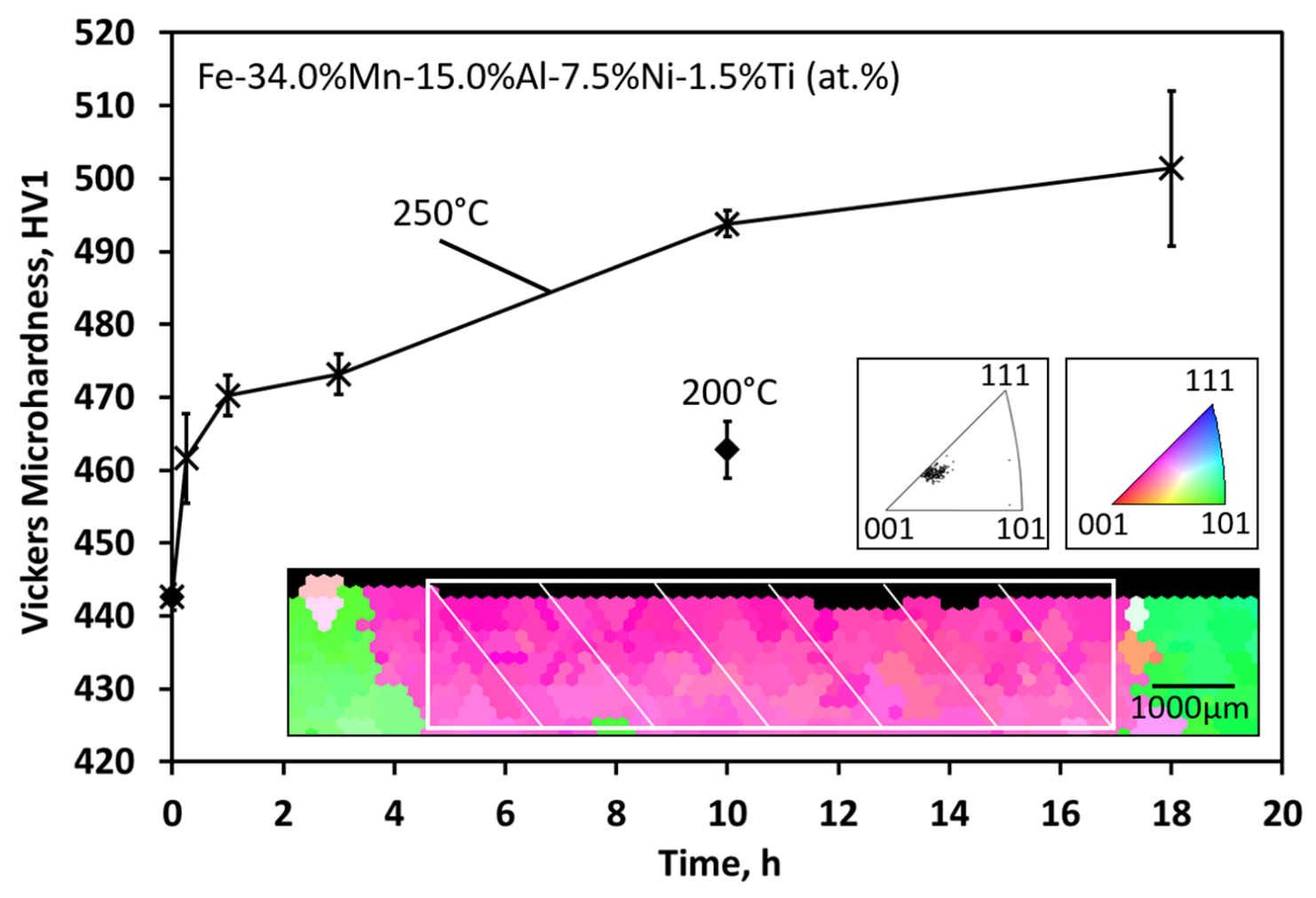

Figure 2 


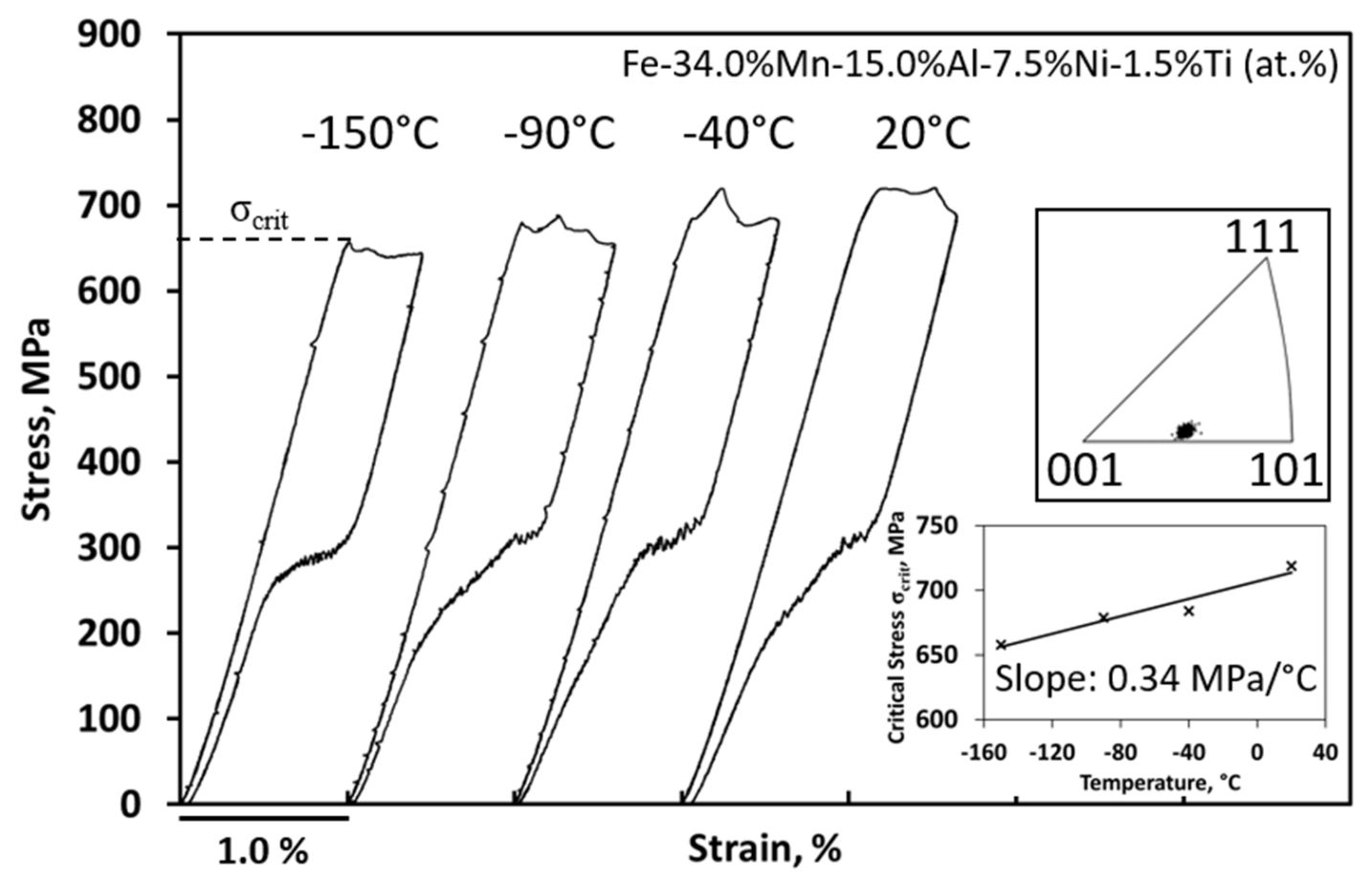

Figure 3 


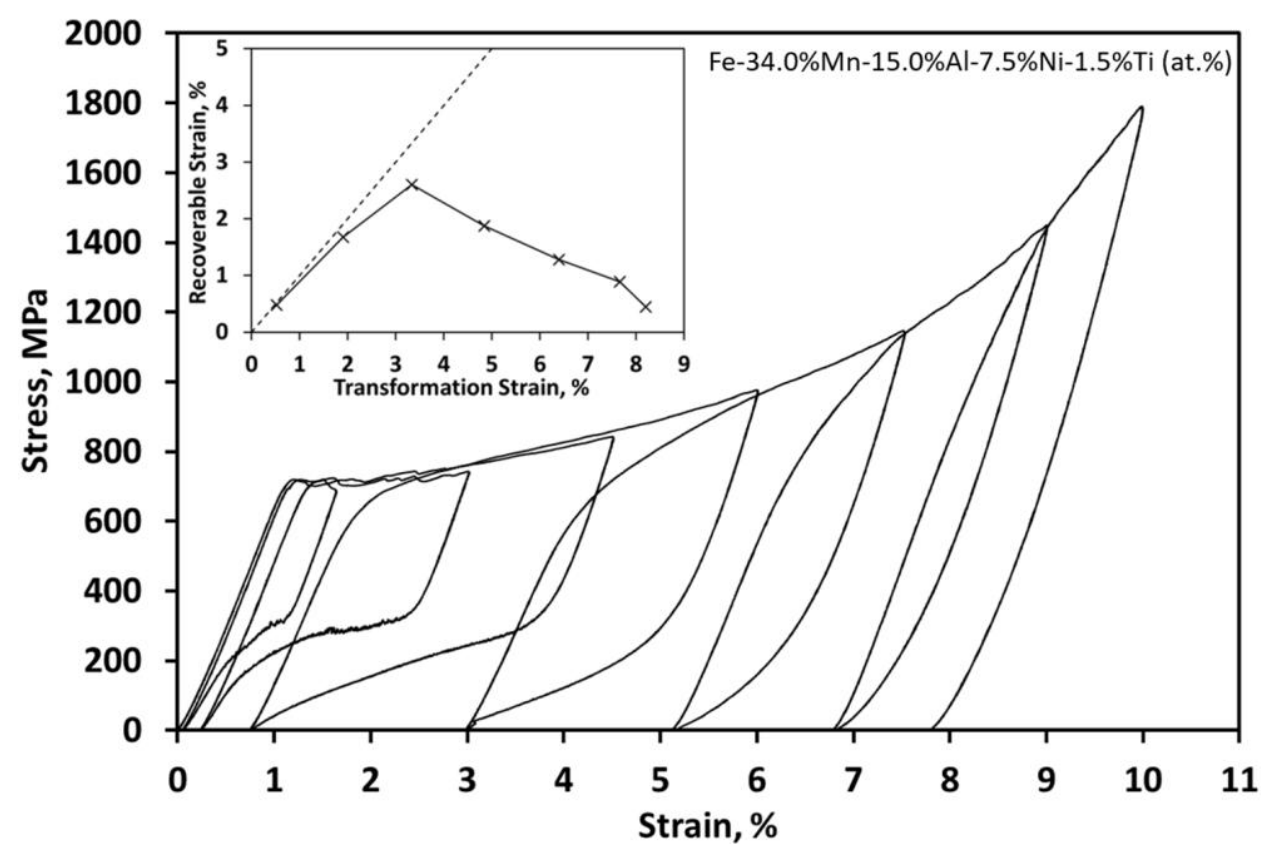

Figure 4 


\section{Graphical Abstract}

The addition of titanium allows the reduction of quenching sensitivity in FeMnAINi-base SMA. Single crystalline samples obtained by abnormal grain growth show excellent pseudoelastic performance
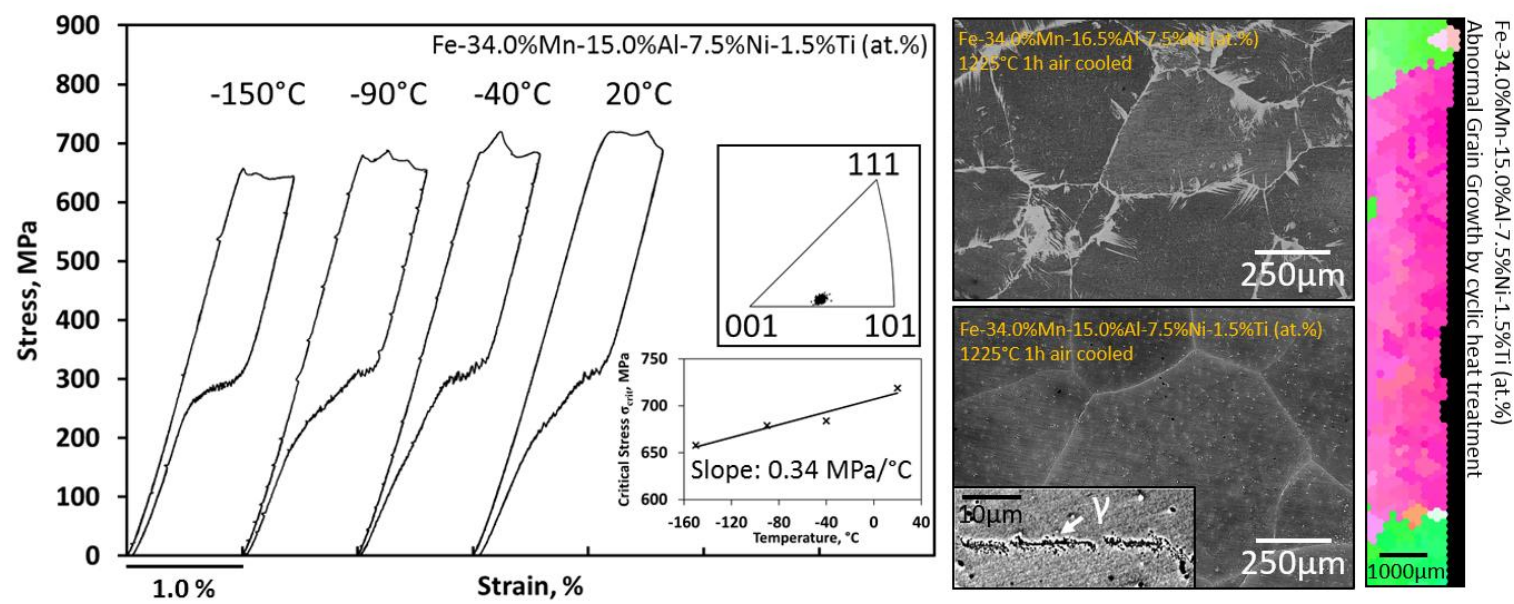